\title{
Electrical and optical properties of phosphorus-doped p-type ZnO films grown by metalorganic chemical vapor deposition
}

\author{
X. H. Pan, J. Jiang, Y. J. Zeng, H. P. He, L. P. Zhu, Z. Z. Ye, ${ }^{\text {a) }}$ and B. H. Zhao \\ State Key Laboratory of Silicon Materials, Zhejiang University, Hangzhou 310027, \\ People's Republic of China \\ X. Q. Pan \\ Department of Materials Science and Engineering, University of Michigan, Ann Arbor, \\ Michigan 48109-2136, USA
}

(Received 2 July 2007; accepted 29 October 2007; published online 22 January 2008)

\begin{abstract}
$\mathrm{P}$-doped $p$-type $\mathrm{ZnO}$ thin films have been grown by metalorganic chemical vapor deposition. By modulating the $\mathrm{P}$ evaporating temperature, $p$-type conductivity can be controlled due to the different $\mathrm{P}$ content incorporated into the $\mathrm{ZnO}$ films. The $\mathrm{P}$-doped $p$-type $\mathrm{ZnO}$ thin films are of high optical quality, as indicated by low-temperature photoluminescence. P-related acceptor state with an energy level of $163 \mathrm{meV}$ is identified from free-to-neutral-acceptor transitions. In addition, x-ray photoelectron spectroscopy confirms that only one chemical bonding state of P exists in the P-doped $\mathrm{ZnO}$ thin films. (C) 2008 American Institute of Physics. [DOI: 10.1063/1.2828017]
\end{abstract}

\section{INTRODUCTION}

$\mathrm{ZnO}$ has gained considerable attention as a promising material for short-wavelength optoelectronic devices, such as photodetectors, light emitting diodes, and laser diodes, due to its wide band gap of $3.37 \mathrm{eV}$ and large exciton binding energy of $60 \mathrm{meV}$ at room temperature. ${ }^{1,2}$ An important issue is the growth of both high quality $p$ - and $n$-type $\mathrm{ZnO}$. However, nominally undoped $\mathrm{ZnO}$ typically exhibits $n$-type conductivity. The realization of $p$-type $\mathrm{ZnO}$ has proven difficult due to the self-compensating effect from native defects and interstitial hydrogen. ${ }^{3,4}$ Fortunately, thanks to the considerable worldwide efforts, investigations on $p$-type $\mathrm{ZnO}$ have proceeded at a rapid pace and various elements have been used as $p$-type dopants, including group-V (Ref. 5-8) and group-I (Ref. 9) elements. Among them, $\mathrm{N}$ appears promising considering its size and energy level. ${ }^{10}$ However, the obtained $p$-type $\mathrm{ZnO}: \mathrm{N}$ films are usually unstable. ${ }^{11}$ The lack of stable $p$-type materials is still the key issue which hinders the development of $\mathrm{ZnO}$-based optoelectronic devices. Recently, a theory for large-sized-mismatched group- $\mathrm{V}$ dopants based on first-principles calculations has been presented. ${ }^{12}$ Also, several groups have reported $p$-type conductivity in $\mathrm{ZnO}$ by doping with large-sized-mismatched impurities, such as $\mathrm{P},{ }^{13}$ As, ${ }^{14}$ and $\mathrm{Sb}^{15}{ }^{15}$ In spite of this progress, the improvement of $p$-type behavior and a better understanding of the doping mechanism in $p$-type $\mathrm{ZnO}$ are strongly demanded for the device development.

Based on our previous study, we develop an effective and reproducible route to prepare $\mathrm{P}$-doped $\mathrm{ZnO}$ by metalorganic chemical vapor deposition (MOCVD), which has many advantages over other growth methods, such as the feasibility of large-area growth and potential industrial application. On the other hand, there are few reports on P-doped $p$-type $\mathrm{ZnO}$ films grown by MOCVD. In this paper, we in-

\footnotetext{
${ }^{a)}$ Author to whom correspondence should be addressed. Electronic mail: yezz@zju.edu.cn.
}

vestigate $p$-type behavior in $\mathrm{P}$-doped $\mathrm{ZnO}$ thin films grown by MOCVD with a special thermal evaporator. The electrical and optical properties of the films are readily presented.

\section{EXPERIMENTAL DETAILS}

P-doped $\mathrm{ZnO}$ thin films were grown on quartz and $n$-type Si (100) substrates using a low-pressure MOCVD system. Diethylzinc was used as the zinc source and $\mathrm{N}_{2}$ was used as the carrier gas. High-purity $\mathrm{O}_{2}(99.999 \%)$ and $\mathrm{P}_{2} \mathrm{O}_{5}$ powder $(99.999 \%)$ were used as the oxygen source and P-dopant source, respectively. A special thermal evaporator was used to evaporate $\mathrm{P}_{2} \mathrm{O}_{5}$. The detailed growth procedures were described elsewhere. ${ }^{16}$ Room-temperature Hall-effect measurements were carried out in the van der Pauw configuration (BIO-RAD HL5500PC). Energy-dispersive spectrometry (EDS) was used to examine the $\mathrm{P}$ content in $\mathrm{ZnO}$ films. Temperature-dependent photoluminescence (PL) measurements were performed on a Fluorolog-3-Tau fluorescence spectrometer, using a 320-nm xenon lamp as the excitation light source. The chemical bonding state of $\mathrm{P}$ was analyzed by x-ray photoelectron spectroscopy (XPS) (Thermo ESCALAB 250, Al $K \alpha$ radiation source $h \nu=1486.6 \mathrm{eV}$ ).

\section{RESULTS AND DISCUSSION}

Figure 1 shows the resistivity, Hall mobility, and carrier concentration of $\mathrm{P}$-doped $\mathrm{ZnO}$ thin films grown on quartz substrates as a function of $\mathrm{P}$ evaporating temperature ranging from 350 to $550{ }^{\circ} \mathrm{C}$. All the films exhibit definitive $p$-type conductivity. Hall measurements have revealed that the optimal result on the insulating quartz is realized at the evaporating temperature of $450{ }^{\circ} \mathrm{C}$, with a resistivity of $14.9 \Omega \mathrm{cm}$, a Hall mobility of $0.227 \mathrm{~cm}^{2} \mathrm{~V}^{-1} \mathrm{~s}^{-1}$, and a hole concentration of $1.84 \times 10^{18} \mathrm{~cm}^{-3}$. Note that the $p$-type behavior is very reproducible, since these results could be consistently repeated. Dependence of electrical properties on the $\mathrm{P}$ evaporating temperature illustrated here may be under- 


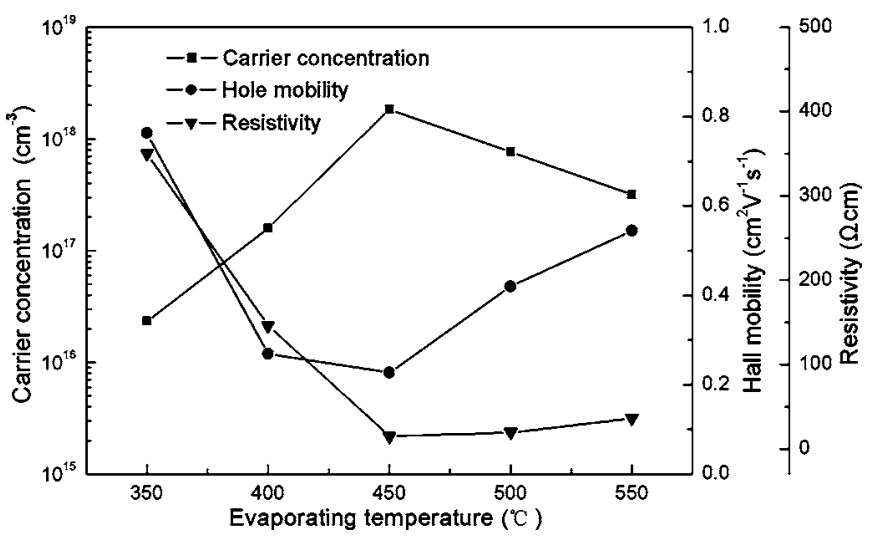

FIG. 1. Dependence of electrical properties of P-doped $\mathrm{ZnO}$ thin films grown on quartz substrates on the $\mathrm{P}$ evaporating temperature.

stood as follows. From EDS analysis, the contents of $\mathrm{P}$ in the $\mathrm{ZnO}$ thin films were calculated to be $0.54 \%, 0.91 \%, 1.43 \%$, $1.21 \%$, and $1.04 \%$, respectively, corresponding to the $\mathrm{P}$ evaporating temperature ranging from 350 to $550{ }^{\circ} \mathrm{C}$. In this regard, the difference of $p$-type conductivity in $\mathrm{P}$-doped $\mathrm{ZnO}$ films may be ascribed to the different $\mathrm{P}$ contents. When the evaporating temperature is low $\left(350{ }^{\circ} \mathrm{C}\right)$, only a part of $\mathrm{P}_{2} \mathrm{O}_{5}$ undergo an evaporation. Thus, the content of $\mathrm{P}$ atoms incorporated in the $\mathrm{ZnO}$ films is relatively low, which is responsible for the relatively high resistivity and low carrier concentration (as shown in Fig. 1). With the evaporating temperature increasing, more $\mathrm{P}_{2} \mathrm{O}_{5}$ evaporate and dissociate, supplying activated $\mathrm{P}$ atoms. As a result, more $\mathrm{P}$ atoms are incorporated into the $\mathrm{ZnO}$ thin films and $p$-type conduction is enhanced gradually. An optimal result is achieved at the evaporating temperature of $450{ }^{\circ} \mathrm{C}$. When the evaporating temperature further increases, especially to $550{ }^{\circ} \mathrm{C}, \mathrm{P}_{2} \mathrm{O}_{5}$ evaporation is very fast, resulting in high concentration of $\mathrm{P}$ existing in the interface of gas and the film. Because of the slow bulk diffusion coefficient, some gaseous $\mathrm{P}$ may flow away with the $\mathrm{O}_{2}$ flowing instead of being incorporated into the $\mathrm{ZnO}$ thin films. Thus, it is reasonable to infer that the $\mathrm{P}$ content decreasing is responsible for the degradation of $p$-type conduction at the high evaporating temperature. A better understanding of this origin is in progress.

To further confirm the $p$-type conduction in $\mathrm{P}$-doped $\mathrm{ZnO}$ thin films, $\mathrm{ZnO}$-based $p-n$ homojunction was fabricated by deposition of a Al-doped $n$-type $\mathrm{ZnO}$ layer on a P-doped $p$-type $\mathrm{ZnO}$ layer grown at the evaporating temperature of $450{ }^{\circ} \mathrm{C}$ on quartz substrate, as illustrated in the inset in Fig. 2. In-Zn alloy was used as both $n$ - and $p$-side electrodes, showing linear current-voltage $(I-V)$ characteristics indicative of good ohmic contacts (date not shown). Figure 2 shows the $I-V$ characteristics of the $\mathrm{ZnO}$ homojunction. The rectification of $I-V$ characteristics, which is very reproducible for repeated measurements, suggests that the fabricated $\mathrm{P}$-doped $\mathrm{ZnO}$ thin film is truly $p$ type.

Hall-effect measurements were performed again 90 days later to investigate the stability of the $p$-type conductivity. It is found that the $\mathrm{P}$-doped $p$-type $\mathrm{ZnO}$ thin films still keep the $p$-type conductivity without any obvious degradation.

To evaluate the acceptor states of $\mathrm{P}$ in $\mathrm{ZnO}$, lowtemperature PL measurements were performed. Figure 3

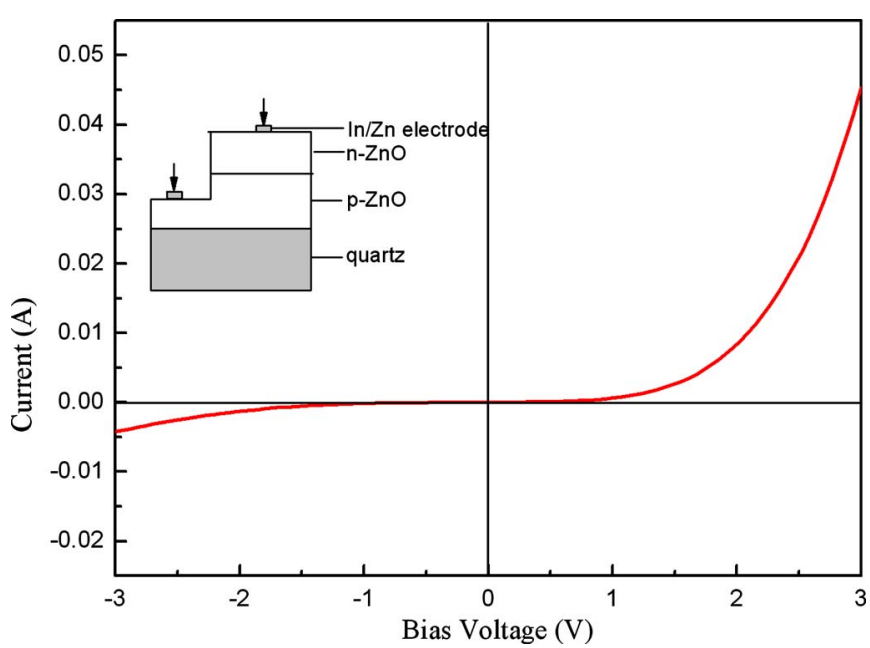

FIG. 2. (Color online) $I-V$ characteristics of Al-doped $\mathrm{ZnO} / \mathrm{P}$-doped $\mathrm{ZnO}$ $n-p$ homojunction measured at room temperature. The inset shows the schematic of the homojunction.

shows the PL spectrum at $8 \mathrm{~K}$ for the $\mathrm{P}$-doped $\mathrm{ZnO}$ thin film grown at the evaporating temperature of $450{ }^{\circ} \mathrm{C}$ on the $n$-type $\mathrm{Si}(100)$ substrate. A strong emission peak at $3.337 \mathrm{eV}$ is dominant in the spectrum, which is labeled as $A$. On the higher energy side, an obvious peak at $3.373 \mathrm{eV}$ is attributed to a free exciton (FX) emission. The evidence of the FX emission suggests a high optical quality. In addition, a peak at $3.271 \mathrm{eV}$ labeled as $B$ with two shoulder peaks at 3.199 and $3.127 \mathrm{eV}$ is also observed. From these peak positions, we tentatively assign band $A$ to a neutral acceptor-bound exciton emission $\left(A^{0} X\right)$, band $B$ to a free-to-neutral-acceptor $\left(e, A^{0}\right)$ transition and the others to its longitudinal opticalphonon replicas.

To gain more information of the origin of the observed emissions, temperature-dependent PL measurements were performed, as shown in Fig. 4. For the FX emission, an obvious temperature-dependent redshift from $3.373 \mathrm{eV}$ at 8 $\mathrm{K}$ to $3.300 \mathrm{eV}$ at $250 \mathrm{~K}$ is observed. While for band $A$, a temperature-dependent blueshift from $3.337 \mathrm{eV}$ at $8 \mathrm{~K}$ to $3.341 \mathrm{eV}$ at $70 \mathrm{~K}$ is observed. We believe that this blueshift

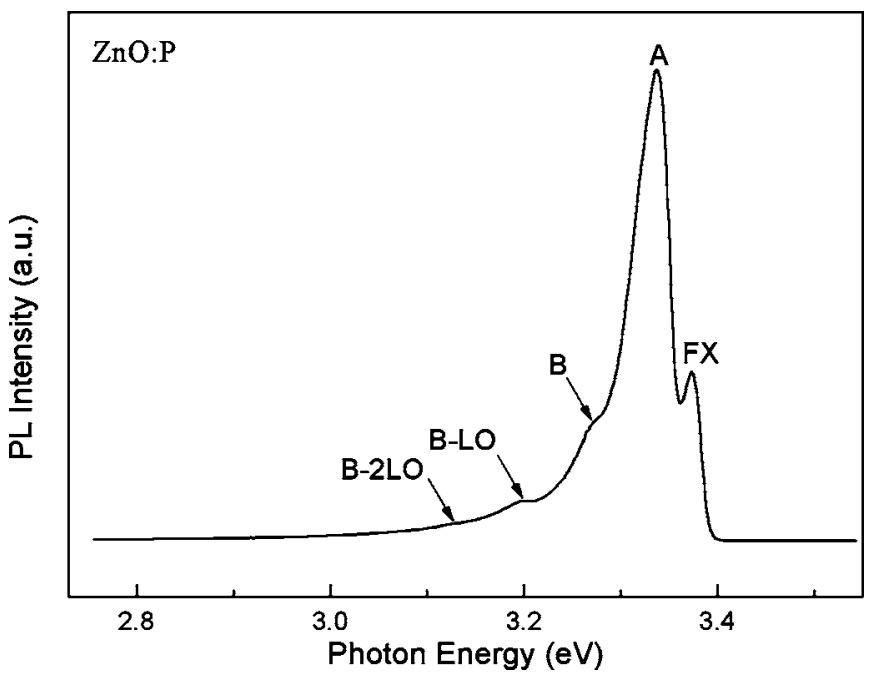

FIG. 3. PL spectrum at $8 \mathrm{~K}$ for the $\mathrm{P}$-doped $\mathrm{ZnO}$ thin film grown at the evaporating temperature of $450{ }^{\circ} \mathrm{C}$ on the $n$-type $\mathrm{Si}$ (100) substrate. 


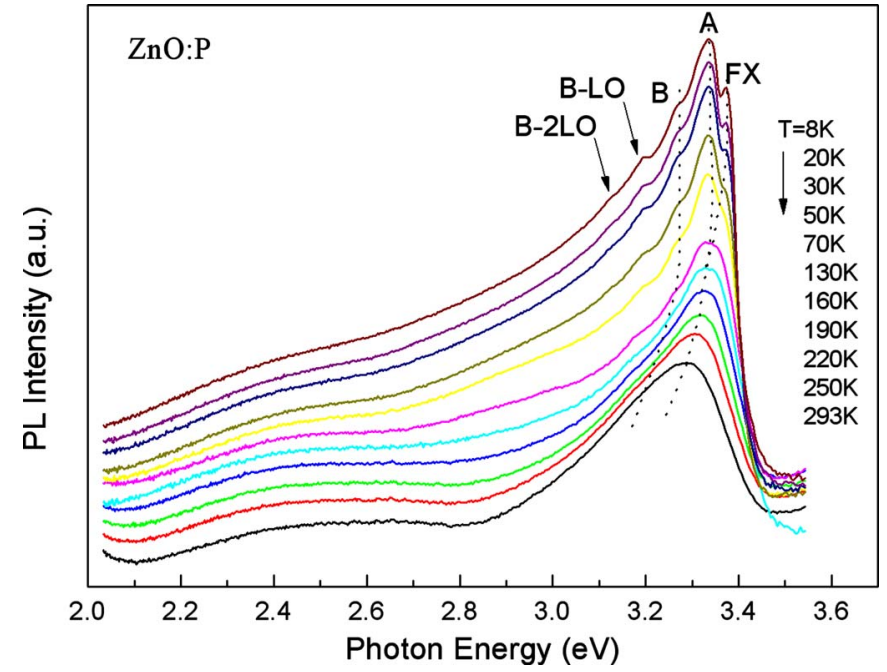

FIG. 4. (Color online) Temperature-dependent PL spectra of the P-doped $p$-type $\mathrm{ZnO}$ thin film grown at the evaporating temperature of $450{ }^{\circ} \mathrm{C}$ on the $n$-type $\mathrm{Si}(100)$ substrate. The dotted lines show the shifts of the $A^{0} X, \mathrm{FX}$ emission and $\left(e, A^{0}\right)$ transitions.

is a result of a transition from bound excition emission to free exciton FX emission mainly due to the thermal dissociation of the $A^{0} X$ at a higher temperature. A similar transition from $A^{0} X$ to $\mathrm{FX}$ emissions has also been observed in GaN, with the transition temperature at $70 \mathrm{~K} .{ }^{17}$ As the temperature further increases, the $A^{0} X$ emission is buried by $\mathrm{FX}$ emission. This clearly suggests that the $A^{0} X$ emission gives way to FX emission at the elevated temperatures due to the thermal effect.

Furthermore, temperature-dependent peak positions of the FX are plotted in Fig. 5. The temperature-dependent band gap is described according to Ref. 18 as

$$
E_{g}(T)=E_{g}(0)-k /[\exp (\theta / T)-1],
$$

where $E_{g}(0)$ is the band gap energy at $0 \mathrm{~K}$. Also, $k$ is a constant and $\theta$ represents the Einstein temperature. A fitting curve of $E_{g}(T)-60 \mathrm{meV}$, as shown in Fig. 5, confirms its typical FX characteristics.

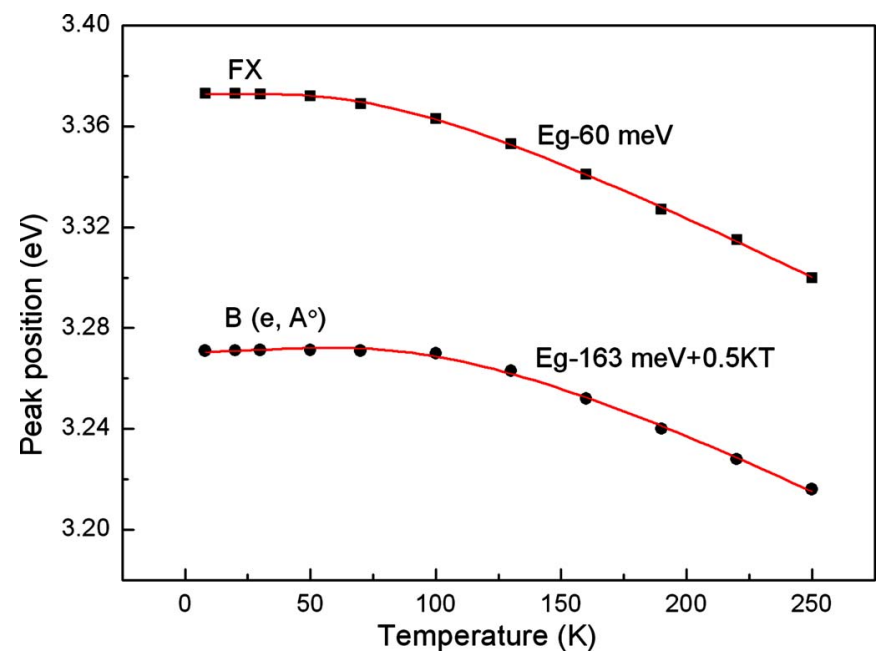

FIG. 5. (Color online) Temperature-dependent peak positions and their fitting curves for $\mathrm{FX}$ and band $B$.

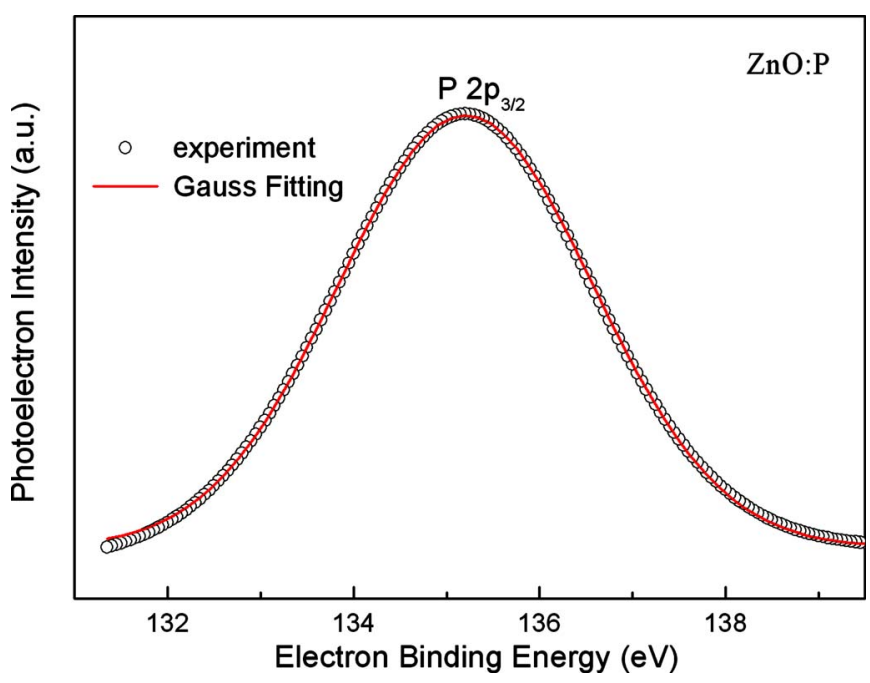

FIG. 6. (Color online) XPS narrow scan spectrum of P $2 p_{3 / 2}$ for the P-doped $p$-type $\mathrm{ZnO}$ thin film grown at the evaporating temperature of $450{ }^{\circ} \mathrm{C}$ on the $n$-type Si (100) substrate.

For $\left(e, A^{0}\right)$ emission, the temperature dependence of the peak position can be well described according to Ref. 19 as

$$
E_{e A}=E_{g}(T)-E_{A}+k_{B} T / 2
$$

where $E_{A}$ is the acceptor energy level and $k_{B}$ is the Boltzmann constant. The fitting to the date gives an acceptor level of $163 \mathrm{meV}$, as shown in Fig. 5. This value agrees fairly well with that reported for P-doped $\mathrm{ZnO}$, such as $180 \mathrm{meV}$ reported by $\mathrm{Xiu}^{20}$ and $127 \mathrm{meV}$ reported by Hwang. ${ }^{21}$ A perfect match between the experimental values and the fitting curves confirms our assignment of the $\left(e, A^{0}\right)$ transitions.

In addition to the earlier mentioned PL measurements, the chemical bonding state of $\mathrm{P}$ in $\mathrm{ZnO}$ thin films was examined by XPS. Figure 6 illustrates the P $2 p_{3 / 2}$ narrow scan spectrum for the $\mathrm{P}$-doped $p$-type $\mathrm{ZnO}$ thin film grown at the evaporating temperature of $450{ }^{\circ} \mathrm{C}$ on the $n$-type $\mathrm{Si}$ (100) substrate. The peak of the P $2 p_{3 / 2}$ core level can be fitted into one Gaussian peak on deducting the base line, which indicates that only one chemical bonding state of $\mathrm{P}$ exists in the $\mathrm{P}$-doped $\mathrm{ZnO}$ thin film. $\mathrm{P} 2 p_{3 / 2}$ peak centered at $135.2 \mathrm{eV}$ is generally attributed to $\mathrm{P}-\mathrm{O}$ bonding. ${ }^{22}$ Therefore, it is concluded that $\mathrm{P}$ incorporated in the film should exist as $\mathrm{P}_{\mathrm{Zn}}$ rather than $\mathrm{P}_{\mathrm{O}}$. However, isolated $\mathrm{P}_{\mathrm{Zn}}$ behaves as a donor rather than an acceptor, which will not result in $p$-type conductivity. Thus, it is reasonable to infer that another P-related acceptor state exists in the P-doped $\mathrm{ZnO}$ thin film. Recently, based on first-principles calculations, a model for large-sizemismatched group- $\mathrm{V}$ dopants in $\mathrm{ZnO}$ has been proposed, ${ }^{12}$ in which a $\mathrm{P}_{\mathrm{Zn}}-2 \mathrm{~V}_{\mathrm{Zn}}$ complex has been considered to be the most likely defect to form a shallow acceptor level. In addition, the P-related acceptor state, with a shallow acceptor level of $163 \mathrm{meV}$, is identified by the previous temperaturedependent PL. With these considerations, the clear $p$-type behavior in the P-doped $\mathrm{ZnO}$ thin film is most likely attributed to the $\mathrm{P}_{\mathrm{Zn}}-2 \mathrm{~V}_{\mathrm{Zn}}$ complex in the present case.

Recently, theoretical calculations give different sentiment toward the outlook of P-doped $\mathrm{ZnO} . \mathrm{Yu}^{23}$ et al. suggested that a possible acceptor $\mathrm{P}_{\mathrm{O}}$ could be formed with an 
energy level of $0.49 \mathrm{eV}$ above the valence band maximum. On the other side, Limpijumnong ${ }^{12}$ proposed a model for large-size-mismatched group- $\mathrm{V}$ dopants in $\mathrm{ZnO}$, in which a $\mathrm{P}_{\mathrm{Zn}}-2 \mathrm{~V}_{\mathrm{Zn}}$ complex has been suggested to be the most likely defect to form a shallow acceptor level. Experimentally, the acceptor activation energy of $\mathrm{P}$-doped $\mathrm{ZnO}$ films is shown to be much smaller than $0.49 \mathrm{eV}$, in the range of $127-180 \mathrm{meV}$. Our experimental results including XPS analysis and PL spectra are in agreement with $\mathrm{P}_{Z n}-2 V_{Z n}$ acceptor state.

\section{CONCLUSIONS}

In summary, we have demonstrated the reproducible growth of P-doped $p$-type $\mathrm{ZnO}$ thin films by MOCVD using $\mathrm{P}_{2} \mathrm{O}_{5}$ as the dopant source. PL spectra reveal that the $p$-type $\mathrm{ZnO}$ films are of high optical quality. A shallow acceptor level of $163 \mathrm{meV}$ is identified from free-to-neutral-acceptor transitions. Guided by XPS, PL, and a model for large-sizedmismatched group- $\mathrm{V}$ dopant in $\mathrm{ZnO}$, a $\mathrm{P}_{\mathrm{Zn}}-2 \mathrm{~V}_{\mathrm{Zn}}$ complex is believed to be the most possible acceptor in the P-doped p-type $\mathrm{ZnO}$ thin films.

\section{ACKNOWLEDGMENTS}

This work was supported by National Basic Research Program of China under Grant No. 2006CB604906 and National Natural Science Foundation of China under Grant No. 50532060 .

${ }^{1}$ Z. K. Tang, G. K. L. Wong, P. Yu, M. Kawasaki, A. Ohtomo, H. Koinuma, and Y. Segawa, Appl. Phys. Lett. 72, 3270 (1998).

${ }^{2}$ D. C. Look, Mater. Sci. Eng., B 80, 383 (2001).

${ }^{3}$ C. G. Van de Walle, Phys. Rev. Lett. 85, 1012 (2000).
${ }^{4}$ A. F. Kohan, G. Ceder, D. Morgan, and C. G. Van de Walle, Phys. Rev. B 61, 15019 (2000).

${ }^{5}$ J. F. Rommeluere, L. Svob, F. Jomard, J. Mimila-Arroyo, A. Lusson, V. Sallet, and Y. Marfaing, Appl. Phys. Lett. 83, 287 (2003).

${ }^{6}$ K. K. Kim, H. S. Kim, D. K. Hwang, J. H. Lim, and S. J. Park, Appl. Phys. Lett. 83, 63 (2003).

${ }^{7}$ D. C. Look, G. M. Renlund, R. H. Burgener, and J. R. Sizelove, Appl. Phys. Lett. 85, 5269 (2004).

${ }^{8}$ L. J. Mandalapu, F. X. Xiu, Z. Yang, D. T. Zhao, and J. L. Liu, Appl. Phys. Lett. 88, 112108 (2006).

${ }^{9}$ Y. J. Zeng, Z. Z. Ye, W. Z. Xu, D. Y. Li, J. G. Lu, L. P. Zhu, and B. H. Zhao, Appl. Phys. Lett. 88, 062107 (2006).

${ }^{10}$ C. H. Park, S. B. Zhang, and S.-H. Wei, Phys. Rev. B 66, 073202 (2002).

${ }^{11}$ T. M. Barnes, K. Olson, and C. A. Wolden, Appl. Phys. Lett. 86, 112112 (2005).

${ }^{12}$ S. Limpijumnong, S. B. Zhang, S.-H. Wei, and C. H. Park, Phys. Rev. Lett. 92, 155504 (2004).

${ }^{13}$ Y. W. Heo, Y. W. Kwon, Y. Li, S. J. Pearton, and D. P. Norton, Appl. Phys. Lett. 84, 3474 (2004).

${ }^{14}$ G. Braunstein, A. Muraviev, H. Saxena, N. Dhere, V. Richter, and R. Kalish, Appl. Phys. Lett. 87, 192103 (2005).

${ }^{15}$ W. Guo, A. Allenic, Y. B. Chen, X. Q. Pan, Y. Che, Z. D. Hu, and B. Liu, Appl. Phys. Lett. 90, 242108 (2007).

${ }^{16}$ J. Jiang, L. P. Zhu, J. R. Wang, X. Q. Gu, X. H. Pan, Y. J. Zeng, and Z. Z. Ye, Mater. Lett. 62, 536 (2008).

${ }^{17}$ C. L. Wu, J. C. Wang, M. H. Chan, T. T. Chen, and S. Gwoa, Appl. Phys. Lett. 83, 4530 (2003).

${ }^{18}$ C. F. Li, Y. S. Huang, L. Malikova, and F. H. Pollak, Phys. Rev. B 55, 9251 (1997).

${ }^{19}$ B. P. Zhang, N. T. Binh, Y. Segawa, Y. Kashiwaba, and K. Haga, Appl. Phys. Lett. 84, 586 (2004).

${ }^{20}$ F. X. Xiu, Z. Yang, L. J. Mandalapu, J. L. Liu, and W. P. Beyermann, Appl. Phys. Lett. 88, 052106 (2006).

${ }^{21}$ D. K. Hwang, H. S. Kim, J. H. Lim, J. Y. Oh, J. H. Yang, S. J. Park, K. K. Kim, D. C. Look, and Y. S. Park, Appl. Phys. Lett. 86, 151917 (2005).

${ }^{22}$ D. T. Clark, T. Fok, G. G. Roberts, and R. W. Sykes, Thin Solid Films 70, 261 (1980)

${ }^{23}$ Z. G. Yu, H. Gong, and P. Wu, Appl. Phys. Lett. 86, 212105 (2005). 